\title{
Computational Simulation of Filters Used in the Removal of Heavy Metals Using Rice Husks
}

\author{
M. C. Barrero-Moreno ${ }^{1}$, C. A. Diaz-Vargas ${ }^{2}$ and E. Restrepo-Parra ${ }^{1, *}$ \\ 1 Department of Physics and Chemistry, Universidad Nacional de Colombia, Research Group in \\ Computational Applications (PCM), Manizales 170003, Colombia; marcbarreromor@unal.edu.co \\ 2 Department of Chemical Engineering, Universidad Nacional de Colombia, Research Group in Chemical, \\ Catalytic and Biotechnological Processes, Manizales 170003, Colombia; caadiazva@unal.edu.co \\ * Correspondence: erestrepopa@unal.edu.co
}

Citation: Barrero-Moreno, M.C.; Diaz-Vargas, C.A.; Restrepo-Parra, E. Computational Simulation of Filters Used in the Removal of Heavy Metals Using Rice Husks. Agriculture 2021, 11, 146. https://doi.org/10.3390/ agriculture11020146

Academic Editor: Yinbo Gan Received: 24 December 2020

Accepted: 29 January 2021

Published: 10 February 2021

Publisher's Note: MDPI stays neutral with regard to jurisdictional claims in published maps and institutional affiliations.

Copyright: (c) 2021 by the authors. Licensee MDPI, Basel, Switzerland. This article is an open access article distributed under the terms and conditions of the Creative Commons Attribution (CC BY) license (https:// creativecommons.org/licenses/by/ $4.0 /)$.

\begin{abstract}
The biofiltration technique is of great importance for the removal of heavy metals. In the present work, a laboratory-scale biofilter was modeled using rice husk as a filter material. The Wolborska model was used to know the dimensions necessary for the biofilter to function. The Langmuir and Freundlich isotherms were performed to quantify the filter adsorption process, showing that the Langmuir isotherms are the ones that present the highest correlation coefficient and best represent the removal process of $\mathrm{Cd}$ (II), Cu (II) and $\mathrm{Cr}$ (VI). According to the Langmuir isotherms, the maximum operating temperature allowed for this model was chosen, which was $303.15 \mathrm{~K}$, because it presents the maximum removal of heavy metals. Regarding the $\mathrm{pH}$ variations for $\mathrm{Cd}$ (II) and $\mathrm{Cu}$ (II), the maximum removal was presented with a $\mathrm{pH}=9.0$ and for $\mathrm{Cr}$ (VI) with a $\mathrm{pH}=3.0$ the maximum removal was presented. According to the rupture curves, the blocking times were obtained for each height: for Cd (II) the highest $t_{b}$ for $h=0.55, \mathrm{Cu}$ (II) the highest $t_{b}$ for $h=0.40$ and for $\mathrm{Cr}(\mathrm{VI})$ the highest $\mathrm{t}_{\mathrm{b}}$ for $\mathrm{h}=0.40$.
\end{abstract}

Keywords: bio filter; Wolborska; lignocellulosic material; pH; Langmuir; Freundlich

\section{Introduction}

Environmental pollution is one of the most serious problems that affects society in the 21st century. Among these difficulties, water contamination by heavy metals is one of the current problems that originates from several human activities, such as wearing to geological process; mining; and industries such as microelectronics, electroplating, battery manufacturing, dyes, chemical products and pharmaceutical products [1-3]. The heavy metals are one of the main pollutants of water, being highly toxic for human beings. It is well-known that the most abundant heavy metals in water are mercury $(\mathrm{Hg})[4]$, nickel (Ni) [5], copper $(\mathrm{Cu})[6]$, plumb $(\mathrm{Pb})$ [7] and chromium $(\mathrm{Cr})$ [8]. Various technologies have been used for the removal of metal ions, among which the following stand out: chemical precipitation, chemical coagulation, oxidation, reduction, ion exchange, filtration, ultrafiltration, nanofiltration, adsorption (activated carbon, zeolites, silica gel), technologies membrane (reverse osmosis), electrochemical treatment (electrodialysis and electrocoagulation) and application of artificial wetlands (some stabilization), among others, resulting in many cases ineffective and expensive $[9,10]$. Consequently, it is important to develop new technologies for the detoxification of said effluents and chemical stabilization of the compound [11]. This is the reason for the development of new technologies based on national raw materials is a pending task for researchers from developing countries like Colombia.

In Colombia, because of its different climates, there is a great variety of possible materials with potential applications as lignocellulosic material. Among the most used materials is banana skin, which has been employed to remove metals such as $\mathrm{Cu}$ (II), $\mathrm{Zn}$ (II), $\mathrm{Co}$ (II), $\mathrm{Ni}$ (II) and $\mathrm{Pb}$ (II) [12] with $49.14 \%$ efficiency; other natural material used is the coffee rusk, that is employed in process for removing $\mathrm{Cu}$ (II), Zn (II) and Cd (II) [13] with 
$58.45 \%$ efficiency. Additionally, using sheep's wool, uranium has been removed [14] and with the rice husk, metals like Cd (II), Zn (II), Co (II), Ni (II), Mn (II) and Hg (II) [15] can be removed with $62.85 \%$ efficiency; additionally, using the rice husk, there are heavy metal removal reports such as $\mathrm{Cd}$ (II), $\mathrm{Cu}$ (II), $\mathrm{Cr}$ (VI), $\mathrm{Pb}$ (II), $\mathrm{Zn}$ (II) and As (III) with adsorption capacities between $72.80 \%$ and $99.30 \%$ [16]. In most previous reports, an additional process of the material is required. Generally, a chemical process is conducted to activate the material, leaving impurities that generate a subsequent contamination [17].

Modeling and simulation processes are a very useful tool because, regard independently of the complexity of the bio filter system, it can be modeled considering most of the variables for reaching an efficient operation. Within the theoretical studies, it is found that the mathematical modeling of a heavy metal adsorption system can evaluate the dynamics regarding the ways that metals adhere to the lignocellulosic material [18]. Additionally, it was found that with a vertical flow filter, a dynamic simulation can be performed to evaluate the transport and destination of heavy metals in wastewater. For modeling systems that remove heavy metals, the following characteristics are considered: volume of residual water, temperature, concentration of heavy metals, contact time and flow [19]. Moreover, it is required to consider an initial concentration, contact time [20], porosity, depth, filtration rate, loss of load, geometry, inlet and outlet pressure and the characteristics of the affluent [21]. Furthermore, the $\mathrm{pH}$ is considered as a fundamental variable, because at high values, the negative sites increase and at low values, the formation of hydroxylated ions decreases as well as the adsorption of heavy metals [22]. Employing a statistical model is proposed for the analysis of adsorption; they found that for the filtering process, a controlled temperature must be maintained, avoiding the deterioration of the system used as a filter [23]; and the efficiency of a filter depends on the characteristics and properties of interactions between the filter and the substance or element that will be retained.

Contaminants are not only found in water; for example, Kalawik et al., [24] reported that heavy metals such as $\mathrm{Hg}, \mathrm{Cd}, \mathrm{Pb}$, As and Ni have been found in foods such as sushi, the concentrations of heavy metals found are high enough to affect the health of people who eat these foods. Traces of $\mathrm{Pb}, \mathrm{Cu}, \mathrm{Cd}$ and $\mathrm{Hg}$ have also been found in meat sold for human consumption [25]. Other studies show how heavy metals such as $\mathrm{Cd}, \mathrm{Pb}$ and as have been the most detected in foods such as vegetables and fruits, presenting a great risk to humans. Due to the large presence of heavy metals both in water and in food, the need arises to propose alternatives for the removal of heavy metals. The alternative that arises in this case is a bio-filter made from easily accessible materials that contribute to a circular economy, such as rice husk, which allows the removal of metals such as $\mathrm{Cr}$ (VI), Cd (II) and $\mathrm{Cu}$ (II) from water. In this work, kinetic models were used for modelling the effectiveness of rice husk as a material used in a filter for the removal of $\mathrm{Cr}$ (VI), $\mathrm{Cd}$ (II) and $\mathrm{Cu}$ (II) in batch processes. The outline of this document is the following: In Section 2, we give the model, the bio filter design, and the explication of selection of lignocellulosic material. In Section 3, isotherms and breaking curves for each heavy metal are presented. Finally, conclusions are given in Section 4.

\section{Materials and Methods}

This section will explain the model used for the bio filter, the design of the bio filter and the explanation of the selection of the material and the characteristics of the rice husk to be used in the removal of metals such as $\mathrm{Cr}$ (VI), $\mathrm{Cd}$ (II) and $\mathrm{Cu}$ (II).

\subsection{Model}

The Wolborska Model [26] is defined as follows:

$$
\operatorname{Ln} \frac{C}{C_{o}}=\frac{\beta_{a} C_{o}}{N_{o}} t-\frac{\beta_{a} z}{U_{o}}
$$


where $C_{o}$ is initial solute concentration $(\mathrm{mg} / \mathrm{L}), C$ is effluent solute concentration $(\mathrm{mg} / \mathrm{L})$, $N_{o}$ is the saturation concentration $(\mathrm{mg} / \mathrm{L}), \beta_{a}$ is the kinetic mass transfer coefficient $\left(\mathrm{min}^{-1}\right)$, $Z$ is the depth of the column $(\mathrm{cm})$ and $U_{o}$ is the surface speed $(\mathrm{cm} / \mathrm{min})$. [27].

\subsection{Isotherms}

For the adsorption process of the bio filter, it was quantified by performing the Langmuir and Freundlich isotherms. Using the Langmuir model, several assumptions are made: (a) the surface is considered homogeneous, (b) it has a saturation point at which no more metals can be absorbed, (c) the heat of adsorption is independent of the degree of coating, and (d) all the sites are equivalent and the energy of the absorbed molecules is independent of the presence of other molecules [28]. The Langmuir isotherm is based on the hypothesis that all active adsorption centers are equivalent and that the ability of a molecule to bind to the surface is independent of whether there are nearby positions occupied; adsorption is restricted to a monolayer and is represented by the following equation:

$$
Q_{e}=Q_{\max } \frac{b C_{e}}{1+b C_{e}}
$$

where $Q_{e}$ is the quantity of metal adsorbed on the surface of the biosorbent $(\mathrm{mg} / \mathrm{g}), C_{e}$ is the amount of metal present in the solution at equilibrium condition $(\mathrm{mg} / \mathrm{L}), Q_{\max }$ is the maximum adsorption capacity of the biosorbent $(\mathrm{mg} / \mathrm{g})$ and $b$ is Langmuir constant representing the affinity (sorption/desorption) of binding sites $(\mathrm{L} / \mathrm{mg})$.

As most surfaces are heterogeneous, there are multiple sites available for adsorption, that is, the heat of adsorption varies from site to site. The Freundlich isotherm, which is expressed according to the following equation:

$$
\log \left(Q_{e}\right)=\log K_{f}+\frac{1}{n} \log C_{e}
$$

where $Q_{e}$ is the quantity of metal adsorbed on the surface of the biosorbent $(\mathrm{mg} / \mathrm{g}), C_{e}$ is the amount of metal present in the solution at equilibrium condition $(\mathrm{mg} / \mathrm{L}), K_{f}$ is a constant indicative of the adsorption capacity of the adsorbent and $\mathrm{n}$ is a constant indicative of the adsorption intensity (restricted to values greater than unity, a range between 2 and 10 represents a good adsorption intensity) [29].

\subsection{Design of the Bio Filter}

The design is based on a dual medium bio filter that has two filter media; one medium allows to remain larger particles and the other medium is used for maintaining smaller particles. The objective of the double media is to eliminate large suspension solids, using sand as a filtering medium and to eliminate heavy metals of small size with various materials, in this case, lignocellulosic materials. Figure 1 shows the structure of the bio filter. In this figure, parts of the system are schematically represented and described as fallows: The distributor is responsible for distributing the flow of water that will enter the filter. The dual media is responsible for retaining waste and heavy metals. Finally, the water that has been filtered with the help of the dual medium is collected in the collector.

The bio filter is in the form of a cylinder to avoid dead areas and allow the water circulates efficiently. From the total filter height, $70 \%$ corresponds to the dual medium ( $40 \%$ rice husk and $30 \%$ anthracite). The distributor $14 \%$, the manifold $6 \%$ and the part where the treated solution circulates corresponds to $10 \%$. Moreover, the bio filter has a cross-sectional area of input and output taking values of 0.28274 and $0.12566 \mathrm{~m}^{2}$, respectively. The surface speed is approximately $0.3 \mathrm{~cm} / \mathrm{s}$. The lignocellulosic material is in a fixed bed adsorption column and the contaminated fluid passes through the bed of the adsorbent. 


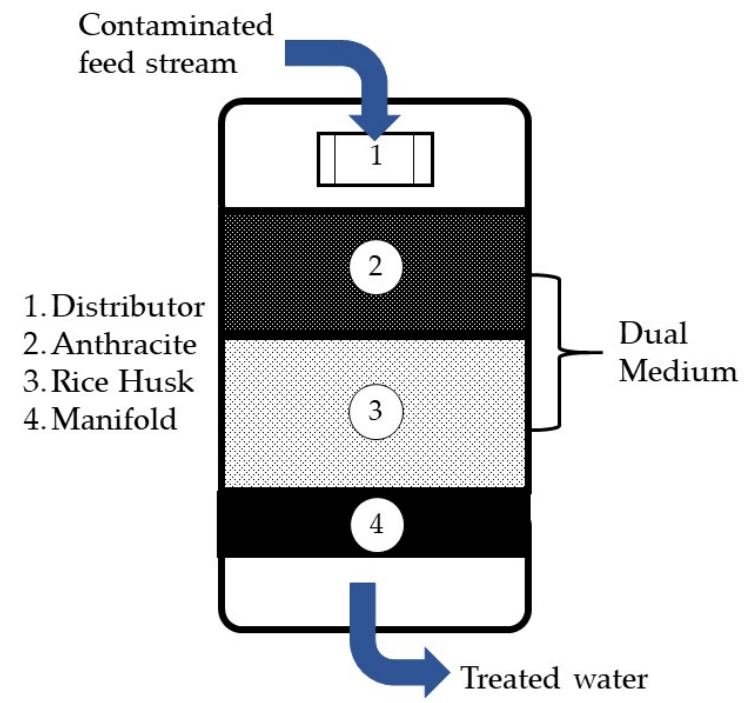

Figure 1. Structure of the bio filter.

According to CERCLA (Comprehensive Environmental Response, Compensation, and Liability Act), the limit of concentrations for the metals to be studied is shown in Table 1.

Table 1. Permitted concentration limit [30].

\begin{tabular}{cc}
\hline Metal & $\operatorname{Co}\left(\frac{\mathbf{m g}}{\mathbf{g}}\right)$ \\
\hline Cr $(\mathrm{VI})$ & 0.01 \\
$\mathrm{Cd}(\mathrm{II})$ & 0.005 \\
$\mathrm{Cu}(\mathrm{II})$ & 1.3 \\
\hline
\end{tabular}

Figure 2 shows a diagram of how the process would be before and after absorption by the rice husk, in which the active sites are represented in gray in which heavy metals are trapped. The heavy metals $\mathrm{Cd}$ (II), $\mathrm{Cr}$ (VI) and $\mathrm{Cu}$ (II) are represented by stars, triangles and squares, respectively, some of them are outside the active sites and that not all are trapped and some that remain free. To be absorbed by the rice husk, processes such as: redox reaction, surprise and ion exchange take place.

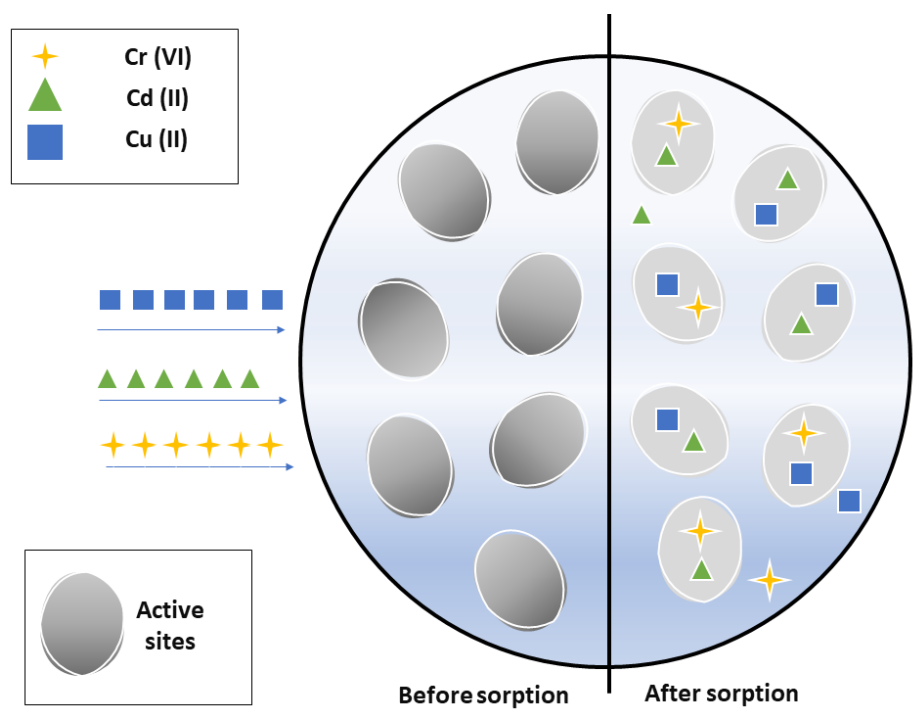

Figure 2. The figure aims to describe the mechanism of absorption of heavy metals. 
The initial concentrations for the metals varied in the following ranges: 0.85 and $10.85 \mathrm{mg} / \mathrm{g}$ for Cd (II), 0.92 and $32.1 \mathrm{mg} / \mathrm{g}$ for Cu (II) and 0.55 and $25 \mathrm{mg} / \mathrm{g}$ for Cr (SAW). The values exceed the permitted limits shown in Table 1 , which is why it is interesting to carry out this type of study that seeks to reduce the concentration of heavy metals.

\section{Results}

For each metal, the isotherms depending on the temperature and the $\mathrm{pH}$ shows in this section. For obtaining the isotherms, the Brunauer-Demming-Demming-Teller classification (BBDT) is taken into account [31]. In addition, the rupture curve that is related to the kinetic equation used to model the operation of the bio filter are developed.

\subsection{Selection of Lignocellulosic Material}

Using lignocellulosic materials, smaller solids can be removed, since it has a small pore size and can trap them. Among the lignocellulosic materials most used for the filtration process are sheep's wool, banana peel, coffee peel, orange peel, lemon peel, sugar cane residues and rice peel. Sheep wool has been used to remove metals such as $\mathrm{Cu}$ (II), $\mathrm{Pb}$ (II) and Cd (II), obtaining a high removal capacity when treating the wool with $\mathrm{NaOH}$ and $\mathrm{Na}_{2} \mathrm{~S}$ [32]. The banana peel that has been used for the removal of $\mathrm{Cu}$ (II), $\mathrm{Cd}$ (II), $\mathrm{Pb}$ (II), $\mathrm{Zn}$ (II), $\mathrm{Ni}$ (II) and $\mathrm{Co}$ (II) with an adsorption order of $\mathrm{Pb}$ (II) $>\mathrm{Ni}$ (II) $>\mathrm{Zn}$ (II) $>$ $\mathrm{Cu}(\mathrm{II})>\mathrm{Co}(\mathrm{II})$, which represents a good alternative because it is a product that occurs in approximately 130 countries, to use the banana peel as an adsorbent activation treatment is required [33]. The coffee husk has been used for removal processes of $\mathrm{Cu}$ (II), $\mathrm{Pb}$ (II), $\mathrm{Cr}$ (VI), Ni (II) and Zn (II), coffee is considered as a possible material since it is abundant in many parts of the world; for example, in 2004, it was considered as the most valuable product exported by developing countries and due to its properties it could be used as adsorbent material [34-37]. Orange peel has been used for the removal of metals such as $\mathrm{Cu}$ (II), $\mathrm{Cd}$ (II), $\mathrm{Pb}$ (II), $\mathrm{Zn}$ (II) and $\mathrm{Ni}$ (II); orange peel is proposed since it is one of the main waste products of the soft drink industries; for use as an adsorbent it requires a special treatment with $\mathrm{CS}_{2}$ so that its $(\mathrm{OH})^{-}$sites can be activated and remove heavy metals [38,39]. With the lemon peel to remove $\mathrm{Pb}$ (II), to use the lemon peel a treatment with citric acid must be done. Using sugarcane, the removal capacity for $\mathrm{Pb}$ (II), $\mathrm{Cd}$ (II) and $\mathrm{Cr}$ (VI) has been studied showing efficiencies of $86 \%, 64 \%$ and $62 \%$, respectively; for the use of sugarcane a chemical treatment is required [40]. Finally, the rice husk to be used to remove metals such as Cd (II), Cr (VI), Cr (III), Cu (II), Mn (II) and Fe (II) [41-43], for use the rice husk in adsorption processes, chemical treatments are not required with a simple washing can be used.

According to the studies conducted, it has been found that rice husk is a material widely used in heavy metal removal processes that demonstrates efficiency and facility in its application. This natural material is described as a viable alternative, economical and accessible to solve pollution problems of heavy metal affluent. Experimentally, the rice husk not requires an activation process to be used as a feasible material for the bio-adsorption process [43]. To use rice husk for the bio filter, the following physical-chemical properties are employed, and values are included in Table 2. For rice husk, the acid sites are more than basic sites. The acidic sites, because of their charge allow the actions to be attracted by the lignocellulosic material and be removed efficiently. The rice husk that is proposed as adsorbent material in the dual medium would not present any additional treatment if it were to be conducted experimentally, since with a simple washing the rice husk could be used as filter material. Additionally, no component was used to maximize specific area and pores. 
Table 2. Texture and physicochemical properties [44].

\begin{tabular}{cc}
\hline Property & Value \\
\hline Specific area $\left(\mathrm{m}^{2} / \mathrm{g}\right)$ & 1219 \\
Pore volume $\left(\mathrm{cm}^{3} / \mathrm{g}\right)$ & 0.59 \\
Average pore diameter $(\mathrm{nm})$ & 2.23 \\
Acid sites (meq/g) & 0.70 \\
Basic sites (meq/g) & 0.28 \\
\hline
\end{tabular}

\subsection{Isotherm Varying Temperature}

Figures 3 and 4 show Freundlich and Langmuir isotherms, respectively. In the isotherms, the temperature was varied $293.15 \mathrm{~K}$ (blue), $298.15 \mathrm{~K}$ (yellow) and $303.15 \mathrm{~K}$ (green) for $\mathrm{Cd}$ (II), $\mathrm{Cu}$ (II) and $\mathrm{Cr}$ (VI), respectively. For the isotherms, the constants corresponding to each type were calculated, as well as the correlation coefficient with which it is observed that isotherm best defines the adsorption process as shown in Table 3 . The isotherm that best describes the proposed bio-filter process is the Langmuir isotherm, because comparing the correlation coefficients, those of Langmuir are better (Table 3 shows that the Langmuir coefficients compared to those of Freundlich are much higher, showing that it is the type of isotherm that best defines the adsorption process of the metals $\mathrm{Cd}$ (II), $\mathrm{Cu}$ (II) and $\mathrm{Cr}(\mathrm{VI})$, as also shown in Figure 4). In works reported experimentally for $\mathrm{Cd}$ (II), $\mathrm{Cu}$ (II) and $\mathrm{Cr}(\mathrm{VI})$, the isotherms that have been used to describe the adsorption process are those of Langmuir [30,41,45-47].

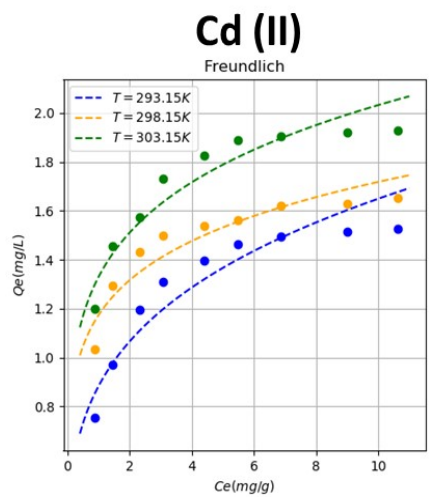

(a)

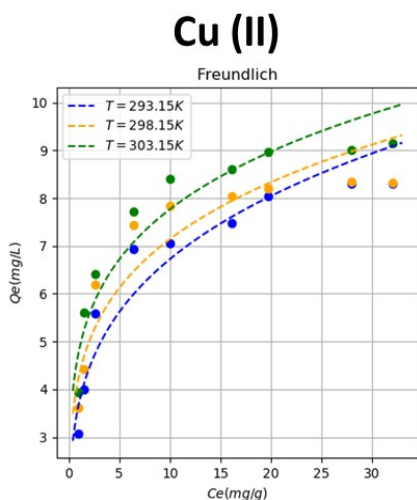

(b)

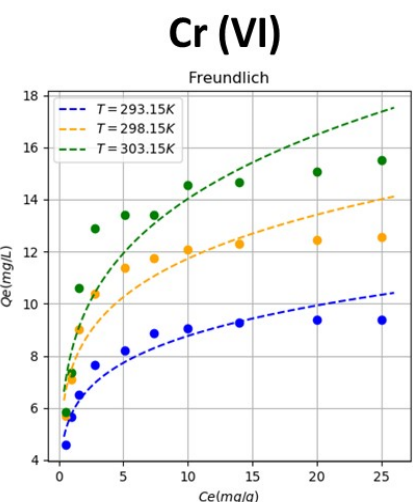

(c)

Figure 3. Isotherm of Freundlich at different temperatures (T) $\mathrm{T}=303.15 \mathrm{~K}$ (green), $\mathrm{T}=298.15 \mathrm{~K}$ (yellow) and $\mathrm{T}=293.15 \mathrm{~K}$ (blue) for (a) Cd (II), (b) Cu (II) and (c) Cr (VI).

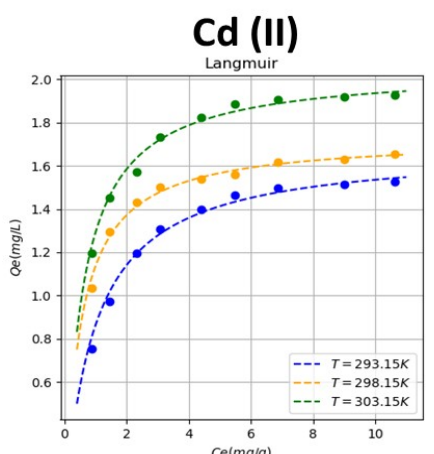

(a)

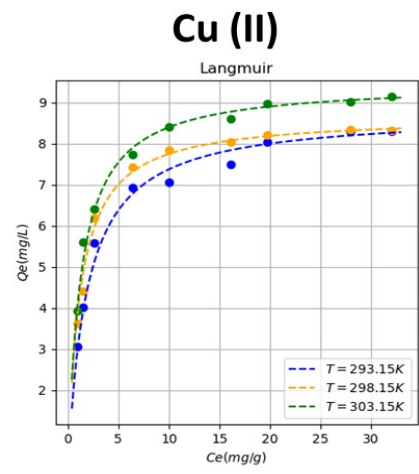

(b)

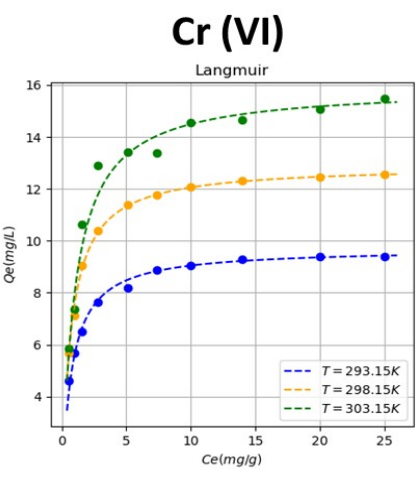

(c)

Figure 4. Isotherm of Langmuir at different temperatures $(\mathrm{T}) \mathrm{T}=303.15 \mathrm{~K}$ (green), $\mathrm{T}=298.15 \mathrm{~K}$ (yellow) and $\mathrm{T}=293.15 \mathrm{~K}$ (blue) for (a) Cd (II), (b) Cu (II) and (c) Cr (VI). 
Table 3. Langmuir and Freundlich parameters.

\begin{tabular}{cccccccc}
\hline \multirow{2}{*}{ Metal } & Temperature & \multicolumn{3}{c}{ Freundlich } & \multicolumn{3}{c}{ Langmuir } \\
\cline { 3 - 8 } & & $\boldsymbol{K}_{\boldsymbol{f}}\left(\frac{\mathbf{L}}{\mathbf{m g}}\right)$ & $\mathbf{n}$ & $\mathbf{R}^{2}$ & $\boldsymbol{b}\left(\frac{\mathbf{L}}{\mathbf{m g}}\right)$ & $\boldsymbol{q}_{\text {max }}\left(\frac{\mathbf{m g}}{\mathbf{g}}\right)$ & $\mathbf{R}^{2}$ \\
\hline \multirow{3}{*}{$\mathrm{Cd}(\mathrm{II})$} & $293.15 \mathrm{~K}$ & 0.88293 & 3.68459 & 0.90350 & 1.05644 & 1.68010 & 0.99910 \\
& $298.15 \mathrm{~K}$ & 1.17351 & 6.0386 & 0.87090 & 1.91261 & 1.73070 & 0.99980 \\
& $303.15 \mathrm{~K}$ & 1.32962 & 5.42593 & 0.91110 & 1.70654 & 2.04960 & 0.99950 \\
$\mathrm{Cu}(\mathrm{II})$ & $293.15 \mathrm{~K}$ & 3.70432 & 3.86249 & 0.91110 & 0.53886 & 8.74125 & 0.99870 \\
& $298.15 \mathrm{~K}$ & 4.27891 & 4.49438 & 0.87770 & 0.83732 & 8.67302 & 0.99980 \\
& $303.15 \mathrm{~K}$ & 4.80424 & 4.79386 & 0.89330 & 0.78222 & 9.46969 & 0.99970 \\
$\mathrm{Cr}(\mathrm{VI})$ & $293.15 \mathrm{~K}$ & 5.77766 & 5.52791 & 0.91600 & 1.38389 & 9.69932 & 0.99990 \\
& $298.15 \mathrm{~K}$ & 7.50673 & 5.15995 & 0.86850 & 1.42463 & 12.90322 & 1 \\
& $303.15 \mathrm{~K}$ & 8.19726 & 4.28816 & 0.84310 & 1.01290 & 15.92356 & 0.99920 \\
\hline
\end{tabular}

The efficiencies for each metal at different temperatures are presented below in Table 4 .

Table 4. Efficiencies of each metal varying temperature.

\begin{tabular}{cccc}
\hline \multirow{2}{*}{ Heavy Metal } & \multicolumn{3}{c}{ Temperature (K) } \\
\cline { 2 - 4 } & $\mathbf{2 9 3 . 1 5}$ & $\mathbf{2 9 8 . 1 5}$ & $\mathbf{3 0 3 . 1 5}$ \\
\hline Cd (II) & $68.7 \%$ & $86.21 \%$ & $86.21 \%$ \\
Cu (II) & $67.11 \%$ & $89.49 \%$ & $89.49 \%$ \\
Cr (VI) & $59 \%$ & $66.37 \%$ & $73.75 \%$ \\
\hline
\end{tabular}

\subsection{Isotherm Varying $p H$}

Figure 5 shows the Langmuir isotherms, taking $\mathrm{pH}$ values of 3.0,6.0 and 9.0, for $\mathrm{Cd}$ (II) and $\mathrm{Cu}$ (II), for $\mathrm{Cr}$ (VI) $\mathrm{pH}$ values of 4.0, 6.0 and 8.0. Only the Langmuir isotherms are shown since according to Table 5 and the previous Figures they are the isotherms that best describe the adsorption of heavy metals on the rice husk. It is very important to take this variable into account in the aqueous medium. For values of $\mathrm{pH}>4.5$, cations are absorbed and at $\mathrm{pH}$ values between 1.5 and 4 , anions are removed. Type I isotherms, as in the figure, is limited by the completion of a single monolayer of adsorbate at the adsorbent surface. Adsorption in all other types do not reach a limit corresponding to the completion of a monolayer.

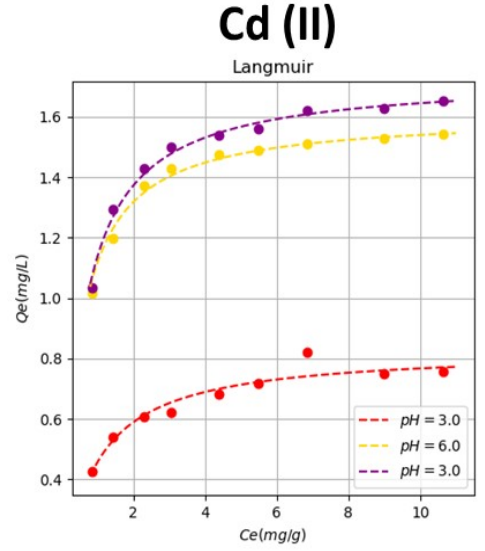

(a)

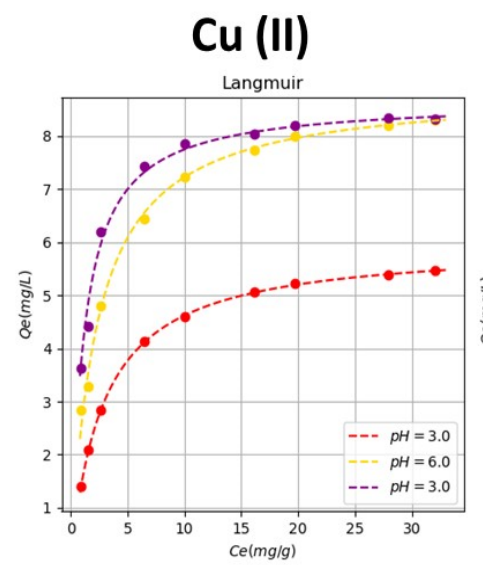

(b)

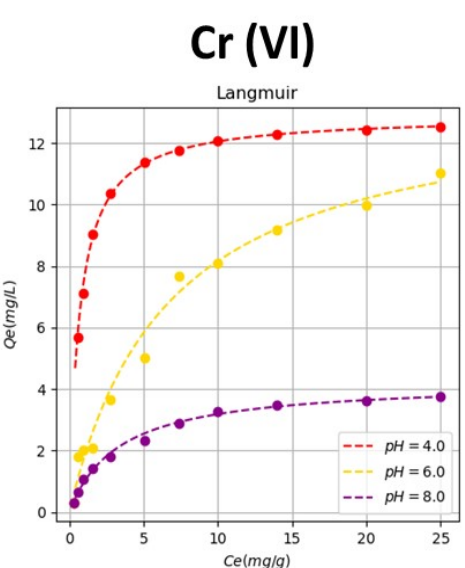

(c)

Figure 5. Isotherm of Langmuir at different pH values (a) Cd (II), (b) Cu (II) and (c) Cr (VI) at 298.15 K. 
Table 5. Langmuir and Freundlich parameters for the isotherms varying the $\mathrm{pH}$.

\begin{tabular}{cccccccc}
\hline \multirow{2}{*}{ Metal } & $\mathbf{p H}$ & \multicolumn{3}{c}{ Freundlich } & \multicolumn{3}{c}{ Langmuir } \\
\cline { 3 - 7 } & & $\boldsymbol{K}_{\boldsymbol{f}}\left(\frac{\mathbf{L}}{\mathbf{m g}}\right)$ & $\mathbf{n}$ & $\mathbf{R}^{2}$ & $\boldsymbol{b}\left(\frac{\mathbf{L}}{\mathbf{m g}}\right)$ & $\boldsymbol{q}_{\text {max }}\left(\frac{\mathbf{m g}}{\mathbf{g}}\right)$ & $\mathbf{R}^{2}$ \\
\hline \multirow{3}{*}{ Cd (II) } & 3.0 & 0.47864 & 4.37445 & 0.90680 & 1.22282 & 0.83015 & 0.99280 \\
& 6.0 & 1.13099 & 6.51041 & 0.86450 & 2.27412 & 1.60720 & 0.99980 \\
& 9.0 & 1.17351 & 6.03864 & 0.87090 & 1.91261 & 1.73070 & 0.99980 \\
$\mathrm{Cu}(\mathrm{II})$ & 3.0 & 1.77588 & 2.75406 & 0.93340 & 0.34604 & 5.95592 & 0.99990 \\
& 6.0 & 3.19280 & 3.25097 & 0.94230 & 0.43626 & 8.88099 & 0.99980 \\
& 9.0 & 4.27891 & 4.49438 & 0.87770 & 0.83732 & 8.67302 & 0.99980 \\
$\mathrm{Cr}$ (VI) & 4.0 & 7.50673 & 5.15995 & 0.86850 & 1.42463 & 12.90322 & 1 \\
& 6.0 & 2.12208 & 1.85288 & 0.96440 & 0.14996 & 13.60544 & 0.96740 \\
& 8.0 & 1.05580 & 2.23964 & 0.95960 & 0.29829 & 4.25531 & 0.99770 \\
\hline
\end{tabular}

Table 5 shows the Langmuir and Freundlich parameters for the isotherms varying the $\mathrm{pH}$. According to the correlation coefficients, the isotherm that best describes the process is Langmuir's, the same as for isotherms varying in temperature. In the case of Cd (II) and $\mathrm{Cu}$ (II) with increasing $\mathrm{pH}, q_{\max }$ increases, showing that at a basic $\mathrm{pH}$ the removal of these metals is favored. In the case of $\mathrm{Cr}(\mathrm{VI})$ the maximum of $q_{\max }$ is presented for $\mathrm{pH}=4.0$ since $\mathrm{Cr}(\mathrm{VI})$ can behave as $\mathrm{Cr}(\mathrm{III})$ under certain conditions of temperature and $\mathrm{pH}$. Regarding the parameter $\mathrm{b}$ that indicates the affinity of the rice husk sites, a $\mathrm{pH}=9.0$ is favored for $\mathrm{Cd}$ (II) and $\mathrm{Cu}$ (II) and for $\mathrm{Cr}$ (VI) with a $\mathrm{pH}=4.0$.

Carrying out the calculations, it was found that, for the temperature established by Table 3 and the different $\mathrm{pH}$ values. Table 6 shows the efficiencies obtained.

Table 6. Efficiencies of each metal varying $\mathrm{pH}$.

\begin{tabular}{cccc}
\hline \multirow{2}{*}{ Heavy Metal } & \multicolumn{3}{c}{$\mathbf{p H}$} \\
\cline { 2 - 4 } & $\mathbf{3 . 0}$ & $\mathbf{6 . 0}$ & $\mathbf{9 . 0}$ \\
\hline $\mathrm{Cd}(\mathrm{II})$ & $83.21 \%$ & $86.21 \%$ & $86.21 \%$ \\
$\mathrm{Cu}(\mathrm{II})$ & $67.11 \%$ & $89.49 \%$ & $89.49 \%$ \\
$\mathrm{pH}$ & 4.0 & 6.0 & 8.0 \\
$\mathrm{Cr}(\mathrm{VI})$ & $92.18 \%$ & $81.12 \%$ & $36.87 \%$ \\
\hline
\end{tabular}

In studies conducted, it was found that, for $\mathrm{Cr}(\mathrm{VI})$ at $\mathrm{pH}=5.0$, percentages of $96 \%$ are calculated. In the case of $\mathrm{Cd}$ (II), the $\mathrm{pH}$ value for an efficient elimination is given with a value close to 5.5 and for the case of $\mathrm{Cu}$ (II) with a $\mathrm{pH}$ of 4.5 , there is a range between approximately $60 \%$ and $90 \%$ efficiency [42]. Comparing the results obtained with those reported in the literature, it is observed that the efficiencies obtained are lower. This behavior is because the rice husk proposed as a filtering medium only requires a wash to be used in the filter, preventing a subsequent contamination. For example, there are reports showing efficiencies of $99 \%$ using rice husk [16]. The high efficiency is attributed to the use of an acid for the activation of the lignocellulosic material, which causes the material to be removed but the water leaves with acid residues. Table 7 shows the values of the final concentrations of the materials based on the efficiencies shown in Table 6.

Table 7. Final concentrations of the heavy metal in rice husk.

\begin{tabular}{cc}
\hline Heavy Metal & Concentrations after Filtering $(\mathbf{m g} / \mathbf{g})$ \\
\hline Cd (II) & 9.35 \\
Cu (II) & 28.72 \\
Cr (VI) & 23.02 \\
\hline
\end{tabular}




\subsection{Efficiency Comparison}

Table 8 is shown below, in which the efficiencies obtained in this work are compared with those reported in the literature for different lignocellulosic materials such as coffee, orange peel, sheep wool and banana peel. Showing that for Cd (II) there are higher efficiencies using orange peel, sheep wool and banana peel which is since these materials are chemically modified to improve their removal efficiencies, with a disadvantage that they generate secondary compounds that contaminate again. In the case of $\mathrm{Cu}$ (II) compared to the other four lignocellulosic materials, the rice husk has less efficiency, indicating that for this metal, other types of materials would be more effective, but one of the bases for modeling the filter with rice husk is that this material does not require activation processes and can be used with a simple wash. Finally, for $\mathrm{Cr}(\mathrm{VI})$ the highest efficiency was presented for the rice husk, showing that it manages to trap $\mathrm{Cr}$ better than the other lignocellulosic materials.

Table 8. Comparison of efficiencies of rice husk with other lignocellulosic materials.

\begin{tabular}{cccccc}
\hline Heavy Metal & Hice Rusk & $\begin{array}{c}\text { Coffee } \\
{[34,48]}\end{array}$ & $\begin{array}{c}\text { Orange Peel } \\
{[49-51]}\end{array}$ & $\begin{array}{c}\text { Sheep Wool } \\
{[51,52]}\end{array}$ & $\begin{array}{c}\text { Banana Peel } \\
\text { [53-55] }\end{array}$ \\
\hline Cd (II) & $86.21 \%$ & $83.5 \%$ & $90 \%$ & $87 \%$ & $89 \%$ \\
Cu (II) & $89.49 \%$ & $97 \%$ & $91 \%$ & $85 \%$ & $72 \%$ \\
Cr (VI) & $92.18 \%$ & $86.66 \%$ & $87.6 \%$ & $90 \%$ & $88 \%$ \\
\hline
\end{tabular}

\subsection{Breaking Curve}

Figure 6 shows the rupture curves that were plotted for the lignocellulosic material at a temperature of $303.15 \mathrm{~K}$, for $\mathrm{Cd}$ (II) (a) and $\mathrm{Cu}$ (II) (b), with $\mathrm{pH}=9.0$; for the case of $\mathrm{Cr}(\mathrm{VI})$, at $\mathrm{T}=303.15 \mathrm{~K}$ and $\mathrm{pH}=4.0$. Figure 6 presents two height values, $\mathrm{h}=0.40$ and $\mathrm{h}=0.55 \mathrm{~m}$, showing that, for the case of $0.40 \mathrm{~m}$, the area of material transferred is much smaller than for $0.55 \mathrm{~m}$, for Cd (II) and Cu (II); nevertheless, for $\mathrm{Cr}$ (VI), the behavior is in opposition. For the rupture curves, there are characteristic parameters such as the breaking time $\left(t_{b}\right)$, that is in the range 0.01 at 0.5 for $C / C_{O}$. At this time, useful capacity of the bed is reached, while the saturation time $\left(t_{s}\right)$ that is in the range 0.95 at 0.99 for $C / C_{O}$, indicates the time for having the total capacity of the bed is reached. The values of $t_{b}$ for $\mathrm{Cd}$ (II), $\mathrm{Cu}$ (II) and Cr (VI) shows in Table 9.
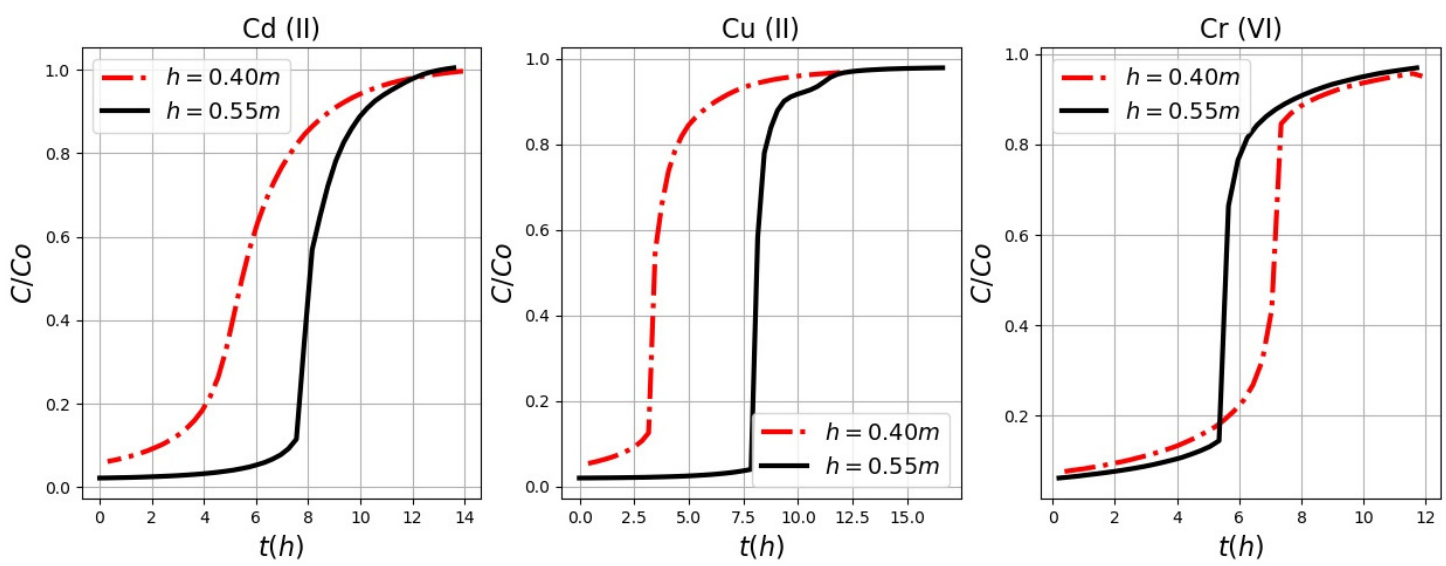

Figure 6. Breaking curves varying height $\mathrm{h}=0.40 \mathrm{~m}$ (points and line) and $\mathrm{h}=0.55 \mathrm{~m}$ (solid line) (a) Cd (II) with $\mathrm{T}=303.15 \mathrm{~K}$ and $\mathrm{pH}=9.0$ (b) $\mathrm{Cu}$ (II) with $\mathrm{T}=303.15 \mathrm{~K}$ and $\mathrm{pH}=9.0$ and (c) $\mathrm{Cr}(\mathrm{VI})$ with $\mathrm{T}=303.15 \mathrm{~K}$ and $\mathrm{pH}=4.0$. 
Table 9. $t_{b}$ varying height for $\mathrm{Cd}$ (II), $\mathrm{Cu}$ (II) and $\mathrm{Cr}$ (VI).

\begin{tabular}{ccc}
\hline \multirow{2}{*}{ Heavy Metal } & Height (h) & $\mathbf{t}_{\mathbf{b}}(\mathbf{h})$ \\
\hline \multirow{2}{*}{ Cd (II) } & 0.40 & 5 \\
& 0.55 & 8 \\
Cu (II) & 0.40 & 7.68 \\
& 0.55 & 3.48 \\
Cr (VI) & 0.40 & 7.8 \\
& 0.55 & 5.61 \\
\hline
\end{tabular}

\section{Discussion}

Varying the temperature, taking the Langmuir isotherm as a reference, it indicates that the adsorption process occurs when a monolayer of the absorbed metal is formed, reaching a saturation point until a quantity of the metal is absorbed. In addition, it indicates that there is an interaction between the molecules adsorbed on the surface of the rice husk, the interactions happen by mechanism such as ion exchange. It is also observed that adsorption occurs at specific active sites that are located on the surface of the rice husk as shown in the filter's operating scheme (Figure 2). Regarding the coefficients that describe the behavior of the Langmuir isotherm, we have $b$ that represents the affinity of the binding sites, which for each metal presents its maximum value at room temperature $(298.15 \mathrm{~K})$ and $q_{\max }$ is the maximum capacity of adsorption of the bio sorbent, which increases with the temperature value showing that up to $303.15 \mathrm{~K}$ the bio-filter works correctly, This is due to the fact that at the reported temperatures $(293.15,298.15$ and $303.15 \mathrm{~K})$ the lignocellulosic material (rice husk) does not deteriorate and does not lose its absorption capacity, if the temperature were increased, there could be inconveniences in terms of to the functioning of the bio-filter that could be evidenced in its adsorption capacity.

According to the isotherms varying the $\mathrm{pH}$, these isotherms describe adsorption processes with microporous solids, which have a very fine porous structure as rice husk. These results indicate that there is a formation of a layer composed of the heavy metal removed, which in this case can be $\mathrm{Cd}$ (II), $\mathrm{Cu}$ (II) or $\mathrm{Cr}$ (VI), which occurs in adsorption. The $\mathrm{pH}$ values that favor removal are higher than 4.5; for $\mathrm{Cd}$ (II) and $\mathrm{Cu}$ (II), this behavior is observed. On the other hand, for $\mathrm{Cr}(\mathrm{VI})$ absorption is favored at $\mathrm{pH}$ values lower than 4 , this is since $\mathrm{Cr}(\mathrm{VI})$ has different valences and in some cases, it behaves like $\mathrm{Cr}$ (III).

According to the rupture curves it is obtained that the capacity at the breaking point increases with the increase in height. The cycle time exhibits typical values between 2 and $24 \mathrm{~h}$; after this time, the lignocellulosic material stops filtering with the same efficiency. These results indicate that useful height values may be $0.55 \mathrm{~m}$ for $\mathrm{Cu}$ (II) and Cd (II). If the height values are reduced, the effect of the axial dispersion phenomenon in the mass transfer predominates; therefore, the metal ions do not have enough time to diffuse throughout the mass of the adsorbent. With a major height, the surface area of the adsorbent contains more binding sites for adsorption. In this type of filter, the water flows through a bed of gravel and sand for long distances, which increases the probability of the solid has contact with other suspended particles, and with the medium formed on the surface of the gravel granule or sand, being thus retained between the filtering material. Later, heavy metals are suspended in the lignocellulosic material. The metal ions must have enough time to be removed and thus im-prove the adsorption capacity of the lignocellulosic material which in this case is the rice husk. Therefore, the higher height favors the removal of heavy metals. For the study of the $\mathrm{Cu}$ (II) removal in a theoretical way, different bed heights were evaluated, finding that the bed height can only determine the total sorption capacity of a fixed bed, which is directly related to the length of service time. This implies that the bed height is one of the main operational factors that control the effluent concentrations of target contaminants in practical field applications [56]. 
For $\mathrm{Cr}(\mathrm{VI})$, the removal is less efficient, since a smaller height should be used compared with $\mathrm{Cd}$ (II) and $\mathrm{Cu}$ (II). The chromium may be retained in the following forms: adsorbed $(\mathrm{Cr}(\mathrm{VI})$ and $\mathrm{Cr}(\mathrm{III}))$, precipitated and bioaccumulated in the support, in the cell membrane and in the metabolites produced by microorganisms [57]. Therefore, in the case of $\mathrm{Cr}(\mathrm{VI})$ it is not enough only to make changes in the height, they must be considered in the other forms that $\mathrm{Cr}(\mathrm{VI})$ can be presented since it decomposes in several ways.

\section{Conclusions}

The application of bio-adsorption in the purification of waters polluted by heavy metals presents a great potential, since lignocellulosic materials can be obtained in large quantities, are cheap and can selectively remove $\mathrm{Cd}$ (II), $\mathrm{Cu}$ (II) and $\mathrm{Cr}$ (VI) of aqueous solutions. The results obtained allow to conclude that rice husk is a good alternative for the implementation of filters with the capacity to remove $\mathrm{Cd}$ (II), $\mathrm{Cu}$ (II) and $\mathrm{Cr}$ (VI) with efficiencies of $83.21 \%, 67.11 \%$ and $92.18 \%$, respectively, for certain values of the height of the filter, temperature and $\mathrm{pH}$. At higher height values, the rupture curves show that the removal process occurs over a longer period and therefore the process is more efficient. Except for $\mathrm{Cr}(\mathrm{VI})$ which, depending on the interactions with the medium, can be converted into $\mathrm{Cr}$ (III) and presents a different behavior than for $\mathrm{Cd}$ (II) and $\mathrm{Cu}$ (II).

\section{Perspectives}

The simulation of the bio-filter using the Thomas model, Bohart-Adams model and Yoon-Nelson model is anticipated as future work. The above, in order to compare the operating parameters of the filter A, possible real-world applications would be in the tributaries near the mining areas in Colombia in regions such as Cordoba, Antioquia or Norte de Santander, which have, as a product or heavy metal by-product, $\mathrm{Cd}$ (II), Cu (II) and $\mathrm{Cr}(\mathrm{VI})$. It is proposed to use in these regions because they are the ones with the highest concentration of heavy metals in the country.

Author Contributions: M.C.B.-M., C.A.D.-V. and E.R.-P. contributed to the writing and editing of this research article. All authors have read and agreed to the published version of the manuscript.

Funding: The authors gratefully acknowledge financial support from the Dirección Nacional de Investigaciones and La Facultad de Ciencias of the Universidad Nacional de Colombia, and Colciencias under the program “Jóvenes Investigadores por la Paz" project number 748.

Institutional Review Board Statement: Not applicable.

Informed Consent Statement: Not applicable.

Data Availability Statement: The data presented in this study are available on request from the corresponding author.

Acknowledgments: Universidad Nacional de Colombia-Sede Manizales and Colciencias.

Conflicts of Interest: The authors declare no conflict of interest.

\section{References}

1. Tchounwou, P.B.; Yedjou, C.G.; Patlolla, A.K.; Sutton, D.J. Heavy Metal Toxicity and the Environment. Exp. Suppl. 2012, 101, 133-164. [PubMed]

2. Mohammed, A.S.; Kapri, A.; Goel, R. Heavy Metal Pollution: Source, Impact, and Remedies. In Water Management and the Environment: Case Studies; Springer Science and Business Media LLC: Dordrecht, The Netherlands, 2011; pp. 1-28.

3. Cook, J. Environmental pollution by heavy metals. Int. J. Environ. Stud. 1977, 10, 253-266. [CrossRef]

4. Arias, F.E.A.; Beneduci, A.; Chidichimo, F.; Furia, E.; Straface, S. Study of the adsorption of mercury (II) on lignocellulosic materials under static and dynamic conditions. Chemosphere 2017, 180, 11-23. [CrossRef] [PubMed]

5. Zhang, X.; Wang, X. Adsorption and Desorption of Nickel(II) Ions from Aqueous Solution by a Lignocellulose/Montmorillonite Nanocomposite. PLoS ONE 2015, 10, e0117077. [CrossRef]

6. Šćiban, M.; Klašnja, M.; Škrbić, B. Adsorption of copper ions from water by modified agricultural by-products. Desalination 2008, 229, 170-180. [CrossRef] 
7. Erdem, M.; Ucar, S.; Karagoz, S.; Tay, T. Removal of Lead (II) Ions from Aqueous Solutions onto Activated Carbon Derived from Waste Biomass. Sci. World J. 2013, 2013, 1-7. [CrossRef]

8. Dupont, L.; Guillon, E. Removal of Hexavalent Chromium with a Lignocellulosic Substrate Extracted from Wheat Bran. Environ. Sci. Technol. 2003, 37, 4235-4241. [CrossRef]

9. Demirbas, A. Heavy metal adsorption onto agro-based waste materials: A review. J. Hazard. Mater. 2008, 157, 220-229. [CrossRef]

10. Chu, K. Improved fixed bed models for metal biosorption. Chem. Eng. J. 2004, 97, 233-239. [CrossRef]

11. Fu, F.; Wang, Q. Removal of heavy metal ions from wastewaters: A review. J. Environ. Manag. 2011, 92, 407-418. [CrossRef]

12. Annadurai, G.; Juang, R.; Lee, D. Adsorption of heavy metals from water using banana and orange peels. Water Sci. Technol. 2003, 47, 185-190. [CrossRef]

13. Oliveira, W.E.; Franca, A.S.; Oliveira, L.S.; Rocha, S.D. Untreated coffee husks as biosorbents for the removal of heavy metals from aqueous solutions. J. Hazard. Mater. 2008, 152, 1073-1081. [CrossRef] [PubMed]

14. Samuel-Nakamura, C.; Robbins, W.A.; Hodge, F. Uranium and Associated Heavy Metals in Ovis aries in a Mining Impacted Area in Northwestern New Mexico. Int. J. Environ. Res. Public Health 2017, 14, 848. [CrossRef] [PubMed]

15. Yang, K.-P.; Mao, X.-Y. A study of nurses' spiritual intelligence: A cross-sectional questionnaire survey. Int. J. Nurs. Stud. 2007, 44, 999-1010. [CrossRef] [PubMed]

16. Zhang, Y.; Zheng, R.; Zhao, J.; Ma, F.; Zhang, Y.; Meng, Q. Characterization of H3PO4-Treated Rice Husk Adsorbent and Adsorption of Copper(II) from Aqueous Solution. BioMed Res. Int. 2014, 2014, 1-8.

17. Ramos, L.P. The chemistry involved in the steam treatment of lignocellulosic materials. Quimica Nova 2003, 26, 863-871. [CrossRef]

18. D'Acunto, B.; Esposito, G.; Frunzo, L.; Mattei, M.R.; Pirozzi, F. Mathematical Modeling of Heavy Metal Biosorption in Multispecies Biofilms. J. Environ. Eng. 2016, 142, 1-14. [CrossRef]

19. Mohammed, A.; Babatunde, A. Modelling heavy metals transformation in vertical flow constructed wetlands. Ecol. Model. 2017, 354, 62-71. [CrossRef]

20. Renu, M.A.; Singh, K.; Upadhyaya, S.; Dohare, R. Removal of heavy metals from wastewater using modified agricultural adsorbents. Mater. Today Proc. 2017, 4, 10534-10538. [CrossRef]

21. Ullah, M.A.; Farooq, S.; Viswanathan, S. Modeling and Simulation of a Biofilter. Ind. Eng. Chem. Res. 1999, 38, $2765-2774$.

22. Burakov, A.E.; Galunin, E.V.; Burakova, I.V.; Kucherova, A.E.; Agarwal, S.; Tkachev, A.G.; Gupta, V.K. Adsorption of heavy metals on conventional and nanostructured materials for wastewater treatment purposes: A review. Ecotoxicol. Environ. Saf. 2018, 148, 702-712. [CrossRef]

23. Tejada-Tovar, C.; Villabona-Ortiz, Á; Garcés-Jaraba, L. Adsorción de metales pesados en aguas residuales usando mate-riales de origen biológico. Tecno Lógicas 2015, 18, 109-123. [CrossRef]

24. Kulawik, P.; Dordevic, D.; Gambuś, F.; Szczurowska, K.; Zając, M. Heavy metal contamination, microbiological spoilage and biogenic amine content in sushi available on the Polish market. J. Sci. Food Agric. 2018, 98, 2809-2815. [CrossRef]

25. Madero, A.; Marrugo, J. Detección de metales pesados en bovinos, en los valles de los rios Sinú y San Jorge, departamento de Córdoba, Colombia. Rev. MVZ Córdoba 2011, 16, 2391-2401. [CrossRef]

26. Wolborska, A. Adsorption on activated carbon of p-nitrophenol from aqueous solution. Water Res. 1989, 23, 85-91. [CrossRef]

27. Hines, A.L.; Maddox, R.N.; Rodríguez Huerta, J.L. Transferencia de Masa: Fundamentos y Aplicaciones; Prentice-Hall Hispanoamericana: Mexico City, Mexico, 1987.

28. Ortega, N.; Nuñez, O. Adsorption of unsatured aldehydes on TiO2. Av. Ciencias Ing. 2012, 3, 81-91.

29. Masel, R.I. Principles of Adsorption and Reaction on Solid Surfaces; John Wiley \& Sons: Hoboken, NJ, USA, 1996.

30. Li, W.C.; Law, F.Y.; Chan, Y.H.M. Biosorption studies on copper (II) and cadmium (II) using pretreated rice straw and rice husk. Environ. Sci. Pollut. Res. 2015, 24, 8903-8915. [CrossRef]

31. Brunauer, S.; Deming, L.S.; Deming, W.E.; Teller, E. On a Theory of the van der Waals Adsorption of Gases. J. Am. Chem. Soc. 1940, 62, 1723-1732. [CrossRef]

32. Enkhzaya, S.; Shiomori, K.; Oyuntsetse, B. Removal of Heavy Metals from Aqueous Solution by Adsorption using Livestock Biomass of Mongolia. J. Environ. Sci. Technol. 2017, 10, 107-119. [CrossRef]

33. Arunakumara, K.; Walpola, B.C.; Yoon, M.-H. Banana Peel: A Green Solution for Metal Removal from Contaminated Waters. Korean J. Environ. Agric. 2013, 32, 108-116. [CrossRef]

34. Anastopoulos, I.; Karamesouti, M.; Mitropoulos, A.C.; Kyzas, G.Z. A review for coffee adsorbents. J. Mol. Liq. 2017, 229, 555-565. [CrossRef]

35. Gusmaroli, L.; Liu, C.; Poch, J.; Fiol, N.; Alberti, G.; Villaescusa, I. A fast and easy approach to the simulation of binary mixtures sorption kinetics. Sci. Total. Environ. 2018, 616, 948-959. [CrossRef]

36. Gomez-Gonzalez, R.; Cerino-Córdova, F.; Garcia-León, A.M.; Soto-Regalado, E.; Dávila-Guzman, N.; Salazar-Rábago, J. Lead biosorption onto coffee grounds: Comparative analysis of several optimization techniques using equilibrium adsorption models and ANN. J. Taiwan Inst. Chem. Eng. 2016, 68, 201-210. [CrossRef]

37. Liu, C.; Fiol, N.; Poch, J.; Villaescusa, I. A new technology for the treatment of chromium electroplating wastewater based on biosorption. J. Water Process. Eng. 2016, 11, 143-151. [CrossRef]

38. Liang, S.; Guo, X.; Feng, N.-C.; Tian, Q.-H. Effective removal of heavy metals from aqueous solutions by orange peel xanthate. Trans. Nonferrous Met. Soc. China 2010, 20, s187-s191. [CrossRef] 
39. Guo, X.; Liang, S.; Tian, Q.-H. Removal of Heavy Metal Ions from Aqueous Solutions by Adsorption Using Modified Orange Peel as Adsorbent. Adv. Mater. Res. 2011, 236-238, 237-240. [CrossRef]

40. Razafsha, A.; Ziarati, P. Removal of Heavy Metals from Oryza Sativa Rice by Sour Lemon Peel as Bio-Sorbent. Biomed. Pharmacol. J. 2016, 9, 543-553. [CrossRef]

41. Eggs, N.; Salvarezza, S.; Azario, R.; Fernández, N.; García, M. Adsorption of hexavalent chromium in the chemically mo-dified rice hask. Av. Ciencias Ing. 2012, 3, 141-151.

42. Zhang, Y.; Zhao, J.; Jiang, Z.; Shan, D.; Lu, Y. Biosorption of Fe(II) and Mn(II) Ions from Aqueous Solution by Rice Husk Ash. BioMed Res. Int. 2014, 2014, 1-10. [CrossRef]

43. Fierro, V.; Muñiz, G.; Basta, A.; El-Saied, H.; Celzard, A. Rice straw as precursor of activated carbons: Activation with orthophosphoric acid. J. Hazard. Mater. 2010, 181, 27-34. [CrossRef]

44. Rangel-Mendez, J.R.; Streat, M. Adsorption of cadmium by activated carbon cloth: Influence of surface oxidation and solution pH. Water Res. 2002, 36, 1244-1252. [CrossRef]

45. Abril, W.J.E. Modelamiento de la Adsorción de Cr+3 sobre un Lecho Fijo. Master's Thesis, Universidad Nacional de Colombia. Facultad de Ciencias, Bogota, Columbia, 2013.

46. Leyva, R.; Flores, J.V.; Díaz, P.E.; Berber, M.S. Adsorción de cromo (VI) en solución acuosa sobre fibra de carbón activado. Inf. Tecnol. 2008, 19, 27-36. [CrossRef]

47. Nahar, K.; Chowdhury, A.K.; Chowdhury, A.H.; Rahman, A.; Mohiuddin, K.M. Heavy metals in handloom-dyeing ef-fluents and their biosorption by agricultural byproducts. Environ. Sci. Pollut. Res. 2018, 25, 7954-7967. [CrossRef]

48. Boudrahem, F.; Soualah, A.; Aissani-Benissad, F. Pb(II) and Cd(II) Removal from Aqueous Solutions Using Activated Carbon Developed from Coffee Residue Activated with Phosphoric Acid and Zinc Chloride. J. Chem. Eng. Data 2011, 56, 1946-1955. [CrossRef]

49. Mendoza, L.V.; Molina, N.F. Biosorción de Cd, Pb y Zn por biomasa pretratada de algas rojas, cáscara de naranja y tuna. Cienc. Ing. Neogranadina 2015, 25, 43-60. [CrossRef]

50. Murugesan, A.; Vidhyadevi, T.; Kirupha, S.D.; Ravikumar, L.; Sivanesan, S. Removal of chromium (VI) from aqueous solution using chemically modified corncorb-activated carbon: Equilibrium and kinetic studies. Environ. Prog. Sustain. Energy 2012, 32, 673-680. [CrossRef]

51. Habib, A.; Islam, N.; Islam, A.; Shafiqul, A.A.M. Removal of Copper from Aqueous Solution Using Orange Peel, Sawdust and Bagasse. J. Anal. Environ. Chem 2007, 8, 21-25.

52. Jumean, F.H.; Khamis, M.; Sara, Z.; AbouRich, M.S. Concurrent Removal and Reduction of Cr(VI) by Wool: Short and Long Term Equilibration Studies. Am. J. Anal. Chem. 2015, 6, 47-57. [CrossRef]

53. Ali, A.; Saeed, K.; Mabood, F. Removal of chromium (VI) from aqueous medium using chemically modified banana peels as efficient low-cost adsorbent. Alex. Eng. J. 2016, 55, 2933-2942. [CrossRef]

54. Anwar, J.; Shafique, U.; Salman, M.; Dar, A.; Anwar, S. Removal of Pb(II) and Cd(II) from water by adsorption on peels of banana. Bioresour. Technol. 2010, 101, 1752-1755. [CrossRef] [PubMed]

55. Hossain, M.A. Removal of Copper from Water by Adsorption onto Banana Peel as Bioadsorbent. Int. J. GEOMATE 2012, 2, 227-234. [CrossRef]

56. Langmuir, I. The Adsorption of Gases on Plane Surfaces of Glass, Mica and Pt. J. Am. Chem. Soc. 1918, 40, 345. [CrossRef]

57. Majumder, S.; Gangadhar, G.; Raghuvanshi, S.; Gupta, S. Biofilter column for removal of divalent copper from aqueous solutions: Performance evaluation and kinetic modeling. J. Water Process. Eng. 2015, 6, 136-143. [CrossRef] 